\title{
Thymoquinone and cisplatin as a therapeutic combination in lung cancer: In vitro and in vivo
}

Syed H Jafri ${ }^{1,2^{*}}$, Jonathan Glass ${ }^{1,2}$, Runhua Shi ${ }^{1,2}$, Songlin Zhang ${ }^{3}$, Misty Prince ${ }^{4}$, Heather Kleiner-Hancock ${ }^{4}$

\begin{abstract}
Background: Thymoquinone (TQ) is a compound extracted from Black Caraway seeds of Nigella Sativa and is active against various cancers. Cisplatin (CDDP) is the most active chemotherapeutic agent in Lung Cancer. Here we report activity of TQ against non-small cell lung cancer (NSCLC) and small cell lung cancer (SCLC) cell lines alone and in combination with Cisplatin (CDDP).
\end{abstract}

Methods: For proliferation MTT assay, cell viability trypan blue assay and for apoptosis Annexin-V FITC assay were used in $\mathrm{NCl}-\mathrm{H} 460$ and $\mathrm{NCl}-\mathrm{H} 146$ cell lines. Inhibition of invasion by TQ was assessed using Matrigel assay and its affect on release of various cytokines was determined using RayBio Human Cytokine detection kit. Mouse xenograft model using $\mathrm{NCl}-\mathrm{H} 460$ was used to determine in vivo activity of TQ and CDDP. Inhibition of LPS induced NF- $\kappa \mathrm{B}$ expression by TQ was determined using transgenic mice expressing a luciferase reporter.

Results: TQ was able to inhibit cell proliferation, reduce cell viability and induce apoptosis. TQ at $100 \mu \mathrm{M}$ and CDDP at $5 \mu \mathrm{M}$ inhibited cell proliferation by nearly $90 \%$ and the combination showed synergism. TQ was able to induced apoptosis in both $\mathrm{NCl}-\mathrm{H} 460$ and $\mathrm{NCl}-\mathrm{H} 146$ cell lines. TQ also appears to affect the extracellular environment inhibiting invasion and reducing the production of two cytokines ENA-78 and Gro-alpha which are involved in neo-angiogenesis. Using a mouse xenograft model we were able to demonstrate that combination of TQ and CDDP was well tolerated and significantly reduced tumor volume and tumor weight without additional toxicity to the mice. In the combination arms (TQ5 mg/kg/Cis $2.5 \mathrm{mg} / \mathrm{kg}$ ) tumor volume was reduced by $59 \%$ and (TQ20 mg/kg/Cis $2.5 \mathrm{mg} / \mathrm{kg}$ ) by $79 \%$ as compared to control which is consistent with in vitro data. TQ down regulated NF- $\kappa$ B expression which may explain its various cellular activities and this activity may prove useful in overcoming CDDP resistance from over expression of NF- $\kappa \mathrm{B}$.

Conclusions: Thus TQ and CDDP appear to be an active therapeutic combination in lung cancer.

\section{Background}

Lung cancer is the leading cause of cancer related death in United States. In the US alone it is estimated that in the year 2008, approximately 215,020 new cases of lung cancer were diagnosed and an estimated 161,480 deaths were reported. The mortality from lung cancer is more than the combined mortality from breast, prostate and colorectal cancers [1].

The two major histological types of lung cancer are non-small cell lung cancer (NSCLC) accounting for about $85 \%$ of cases and small cell lung cancer (SCLC) accounting for $15 \%$ of cases [2]. Approximately $16 \%$ of NSCLC patients are diagnosed with early stage or

\footnotetext{
* Correspondence: sjafri@lsuhsc.edu

${ }^{1}$ Feist-Weiller Cancer Center, Louisiana State University, 1501 Kings Highway, Shreveport LA, 71130 USA
}

localized disease and are treated with surgical resection [3]. Systemic chemotherapy is indicated in adjuvant treatment [4] as well as in advanced stages of NSCLC and is also used in treatment of all stages of SCLC. The most active chemotherapeutic agent for the treatment of NSCLC and SCLC is cisplatin (CDDP) which is used in a doublet with other agents such as paclitaxel, gemcitabine and docetaxel [5]. The response rate in NSCLC from CDDP alone is about $20 \%$ and in combination with a second agent improves to about $26 \%$ [6].

Recently, new agents have been approved for treatment of lung cancer including erlotinib [7] and bevacizumab [8]. However the overall 5 year survival from lung cancer has not changed appreciably in the past 25 years and remains dismal at $16 \%$ [1]. 
The Black Caraway seed also known as (Nigella Sativa, Ranunculaceae family), is an annual herb that grows in countries bordering Mediterranean Sea, Pakistan and India.

The seed has been used as a natural remedy for more than 2000 years to promote health and treat diseases. Medicinal properties of black seeds have even been mentioned by the Prophet of Islam, Muhammad (Peace be upon him) and its use was recommended for various ailments [9].

Thymoquinone (TQ) is the bioactive constituent of the volatile oil of black seed. It has been shown to exert anti-inflammatory, anti-oxidant and anti-neoplastic effects both in vitro and in vivo [10]. TQ has been shown to exhibit anti-tumor activities on cells lines derived from ovarian, breast and colon cancers [11].

TQ has also been shown to potentiate the anti-tumor activity of CDDP in Ehrlic ascites sarcoma (EAC) and simultaneously protected against CDDP nephrotoxicity [12]. Using both mouse and other rodent models it was shown that TQ when administered orally after mixing in drinking water ameliorated the nephrotoxicity from CDDP and also improved CDDP therapeutic index.

Combining the most active chemotherapeutic drugs with agents that target specific pathways offers a powerful approach to cancer treatment and may counteract the many ways that human cancer cells can become drug resistant. The platinum atom of CDDP forms covalent bonds to the N7 positions of purine bases to afford primarily 1, 2- or 1,3-intra strand cross links and a lower number of inter strand cross links which eventually leads to apoptosis [13]. There is evidence that CDDP induces increased expression of NF- $\kappa \mathrm{B}$ and that this activity results in increased CDDP resistance [14].

NF- $\kappa$ B controls cellular proliferation in part by increasing expression of cyclin D1 which moves cells from G1 to $S$ phase [15]. TQ has been reported to suppress tumor necrosis factor (TNF) induced NF- $\kappa \mathrm{B}$ expression in human chronic myeloid leukemia cells (KBM-5) which may also explain why cells undergo apoptosis [16]. TQ was shown to suppress expression of NF- $\kappa \mathrm{B}$ activation pathway through modulation of p65 subunit of NF- $\kappa \mathrm{B}$ and inhibition of $\mathrm{I} \kappa \mathrm{B} \alpha$ kinase (IKK) [16].

Thus in the present study we have combined a noncell cycle specific active chemotherapy drug CDDP which causes direct DNA damage with another agent TQ which targets the cell cycle at the transition from G1 to $S$ phase hypothesizing the combination of TQ and CDPP will enhance the efficacy of CDDP and possibly overcome its resistance by suppression of CDDP induced over expression of NF- $\kappa \mathrm{B}$. TQ by suppressing $\mathrm{NF}-\kappa \mathrm{B}$, should also affect tumor angiogenesis and metastasis [15].

\section{Materials and methods In Vitro experiments Cell culture}

NSCLC cell line NCI-H460 was generously provided by Dr James A. Cardelli (Louisiana State University Health Sciences Center, Shreveport, LA). SCLC cell line NCIH146 was purchased from American Type Culture Collection (ATCC). Cells were grown in RPMI 1640 (Cell gro) supplemented with $10 \%$ Fetal bovine serum (FBS), $1 \%$ Penicillin and Streptomycin in a humidified incubator with $5 \% \mathrm{CO} 2$ at $37^{\circ} \mathrm{C}$.

\section{1) Cell proliferation assay}

NCI-H460 cells (NSCLC cell line) were seeded at a density of 5,000 cells per well in 96 well plates and after 24 hrs cells were treated with $80 \mu \mathrm{M}$ and $100 \mu \mathrm{M}$ Thymoquinone (TQ) (Sigma Aldrich, St Louis MO) in $0.1 \%$ DMSO, $1.25 \mu \mathrm{M}, 2.5 \mu \mathrm{M}$ and 5.0 $\mu \mathrm{M}$ Cisplatin (CDDP) (Sigma Aldrich, St Louis MO) or TQ and CDDP at various combinations as noted. These doses of TQ and CDDP were chosen based on IC50 calculated from earlier experiments (Results not shown). There were four wells per condition and experiment was repeated twice to validate results. MTT (3-(4,5 Dimethylthiazol -2-yl)2,5-dipheynyltetrazolium bromide) assay was used to determine live cells at 24, 48 and 72 hrs after treatment as per the manufacturer's (Invitrogen) instructions.

\section{2) Cell viability assay}

Cell viability of the SCLC cell line NCI-H146 was assessed using the trypan blue cell viability assay. About 5,000 cells/well were seeded in 6 well plates using appropriate media and left in incubator overnight. At 24 hrs cells were treated with TQ at doses 20, 40, 60, 80 and $100 \mu \mathrm{M}$ with appropriate DMSO concentration as the control. Cells were collected 2 hours later by low speed centrifugation and trypan blue viability assay was performed with the aid of a Coulter counter.

\section{3) Apoptosis assay}

Apoptosis in the NCI-H460 and NCI-H146 cell lines was detected using Annexin-V FITC Apoptosis detection kit I (BD Pharmingen). $24 \mathrm{hrs}$ after treatment with $100 \mu \mathrm{M}$ TQ both cell lines were removed from the plates using trypsin in the case of NCI-H460 only. Cells were extensively washed with PBS and adjusted to $1 \times$ $10^{6}$ cells/ml and stained with Annexin V FITC and propidium iodine as per the manufacture's instruction. Presence of apoptosis was detected using a Cytomics FC 500 Beckman Coulter Flowcytometry (Coulter, Inc, Hialeah Fl).

\section{4) Cytokine Assay}

The effect of TQ on release of cytokines was assessed using the RayBio Human Cytokine Antibody Array C Series 2000. (RayBio Tech. Inc. Norcross, GA). Cells grown in serum free media in 12 well plates at a density 
of 5,000 cells/well were treated with DMSO or TQ 100 $\mu \mathrm{M}$ and the media collected after 24 hours. The collected media was applied on cytokine membranes which were then exposed to a photographic film for approximately 30 minutes after which the films were developed in a dark room. The resulting images were analyzed using Image J Software to measure expression of various cytokines.

\section{5) Invasion assay}

The effect of TQ on tumor cell invasion was assayed using a Matrigel based assay. Trans well inserts (Corning Life Science, Corning, NY) with 8 micron diameter pores were coated with $20 \mu \mathrm{L}$ of Matrigel (BD Biosciences), dried, and subsequently rehydrated first using $750 \mu \mathrm{L}$ of serum free medium, followed by the addition of complete medium. NCI-H460 cells at a density of 25,000 cells in $100 \mu \mathrm{L}$ per insert were applied. After 2 hrs cells were treated with DMSO or TQ at 20, 40 or $80 \mu \mathrm{M}$. After $24 \mathrm{hrs}$ the non-invasive cells were removed and the cells that had invaded into the Matrigel were detected by fixation with $10 \%$ neutral buffered formalin followed by staining with hematoxylin. Membranes were removed from inserts, mounted on slides and invading cells counted using a microscope with a $40 \times$ objective.

\section{6) In Vivo Experiments}

a) Animals 5-6 weeks old female Severe combined immunodeficiency mice (SCID) mice were obtained from Harlan Laboratory (Harlan Laboratories, Inc, Indianapolis, IN) and maintained under pathogen free conditions in a temperature and humidity controlled animal care facility with a 12 hours light dark cycle. The animal protocol for this experiment has been approved by the Committee of Animal Care and Use, LSUHSC in accordance with National Institutes of Health (NIH) guidelines. All procedures were conducted under sterile conditions. Mice were allowed access to sterile food and water ad libitum.

b) Maximum Tolerated Dose Groups of 3 or 4 female SCID mice were randomized to receive TQ alone or in combination with CDDP. TQ was prepared by dissolving in cremophor: ethanol: PBS (1:1:4) and CDDP was prepared by dissolving in PBS. TQ was given at 5, 10 and $20 \mathrm{mg} / \mathrm{kg}$ subcutaneously (s.c.) on Monday, Wednesday and Friday for 3 weeks either alone or in combination with CDDP at $5 \mathrm{mg} / \mathrm{kg}$ i.p once a week for 3 weeks. MTD was considered the highest dose in which no mortality was observed. At the end of three weeks mice were sacrificed and liver and kidneys were harvested for histological analysis.

c) Mouse xenograft experiment For the xenograft study, female SCID mice (age 5-6 weeks old) were shaved on the flank two days prior to injection with tumor cells. Xenografts were obtained by injecting NCI-
H460 $2 \times 10^{6}$ cells subcutaneously into the right flank of each mouse. Tumors were allowed to grow for one week and when tumor volume reached approximately $20 \mathrm{~mm}^{3}$ mice were randomized to 6 groups with 10 mice in each group. Tumor volume was calculated using the formula $\mathrm{V}=\left(\mathrm{L} \times \mathrm{W}^{2}\right) \times 0.5$ where $\mathrm{V}=$ volume, $\mathrm{L}=$ length, $\mathrm{W}=$ width.

Mice were randomized into following 6 treatment groups with 10 mice in each group and treated for 3 weeks.

1) Control

2) TQ alone $5 \mathrm{mg} / \mathrm{kg}$ (s.c) $\mathrm{M}, \mathrm{W}, \mathrm{F}$

3) TQ alone $20 \mathrm{mg} / \mathrm{kg}$ (s.c) M, W, F

4) CDDP alone $2.5 \mathrm{mg} / \mathrm{kg}$ (i.p) every Monday

5) CDDP $2.5 \mathrm{mg} / \mathrm{kg}+\mathrm{TQ} 5 \mathrm{mg} / \mathrm{kg}$ (combination)

6) CDDP $2.5 \mathrm{mg} / \mathrm{kg}+\mathrm{TQ} 20 \mathrm{mg} / \mathrm{kg}$ (combination)

Tumor volume and body weight was measured $\mathrm{M}, \mathrm{W}$, F for three weeks during the course of study. At the end of three weeks (Day 26) mice were sacrificed by $\mathrm{CO} 2$ asphyxiation in a pre charged chamber and tissue samples were obtained for histological analysis. Mean tumor weight was also calculated after harvesting tumors.

\section{7) $N F-\kappa B$ expression in lung cancer xenografts}

$\mathrm{NF}-\kappa \mathrm{B}$ in the xenografts was assayed by Western blot analysis on snap-frozen xenograft tumor specimens which were pooled in duplicate for a total of 5 samples per group. Briefly, aliquots of the xenograft samples were lysed in Radio-Immunoprecipitation Assay_RIPA (Buffer) containing protease and phosphatase inhibitor cocktails and EDTA (Thermo Scientific, Rockford, IL). Proteins $(40 \mu \mathrm{g})$ were resolved by SDS-PAGE [17] and the proteins were transferred electrophoretically to PVDF membranes $(0.45 \mu \mathrm{m}$, Millipore Corp., Billerica, MA) [18]. Western blot assays were conducted using antibodies against phospho-Ser529 NF- $\kappa \mathrm{B}(1: 200)$ and unphosphorylated NF- $\kappa \mathrm{B}$ (1:500), followed by the appropriate secondary antibodies and enhanced chemiluminescent detection [19]. The intensities of immunostained proteins were determined using Image J software http://rsb.info.nih.gov/ij/ mean intensities calculated as a ratio of phospho-NF- $\kappa \mathrm{B}$ to total NF- $\kappa \mathrm{B}$, and normalized to Hela cell lysates run on the same gel. 8) $N F-\kappa B$ suppression by $T Q$

We assessed suppression of NF $-\kappa \mathrm{B}$ by TQ using the light producing animal model (LPTA) NF- $\kappa \mathrm{B}-\mathrm{RE}-\mathrm{luc}$ (Oslo) which is a transgenic mice expressing a luciferase reporter whose transcription is dependent on NF- $\kappa \mathrm{B}$ [20]. The luminescence from luciferase can be detected real time using an ultrasensitive camera IVIS 100 Imaging system (Caliper Life sciences, Hopkinton MA). Lipopolysaccharide (LPS) or Tumor necrosis factoralpha $(\mathrm{TNF}-\alpha)$ are used to induce NF- $\kappa \mathrm{B}$ activity. 
Initially 5-8 mice/group were injected with either vehicle alone or TQ $5 \mathrm{mg} / \mathrm{kg}$ or $20 \mathrm{mg} / \mathrm{kg}$ subcutaneously and images obtained to detect any effect of TQ on NF- $\kappa \mathrm{B}$ expression with $2.5 \mathrm{mg}$ D-luciferin substrate administered 15 minutes prior to each imaging without prior induction with LPS. Two days later mice were injected with vehicle or $5 \mathrm{mg} / \mathrm{kg}$ or $20 \mathrm{mg} / \mathrm{kg}$ TQ subcutaneously, followed 30 minutes later by injection of LPS (2.7 $\mathrm{mg} / \mathrm{kg}$ i.p) with mice then imaged at $3 \mathrm{hrs}$ and 24 hrs interval to assess NF- $\kappa \mathrm{B}$ activity with $2.5 \mathrm{mg}$ D-luciferin substrate administered 15 minutes prior to each imaging. The luminescence intensity was quantitated in regions of interest (ROI) using Living Image ${ }^{\circledR} 3.0$ software (Caliper Life Sciences, Inc. Hopkinton, MA).

\section{Statistical analysis}

For the MTT assay factorial analyses of variance (ANOVA) were used to determine the effect of TQ, CDDP and control with the time. Student-NewmanKeuls test was used to determine statistical significance with $\mathrm{P}$ value $<0.05$ considered significant.

For the mouse xenograft studies and for NF- $\kappa \mathrm{B}$ expression using the luciferase reporter mouse $\mathrm{SAS}^{\oplus}$ Proc Mixed was used and least squares means (LSmeans) were estimated. The Bonferroni method was used for multiple comparisons adjustments on the differences of LS-means.

\section{Results}

1) TQ inhibits proliferation alone and in combination with CDDP

In the MTT assay TQ at 80 and $100 \mu \mathrm{M}$ showed significant inhibition of cell proliferation most noticeable at 24 hrs. The effect of TQ alone on cell proliferation waned with time with less activity observed at 48 and $72 \mathrm{hrs}$ suggesting more frequent dosing of TQ may be required to demonstrate a sustained effect. CDDP alone at $24 \mathrm{hrs}$ was not every active as compared to TQ but at 48 and 72 hrs showed significant inhibition of cell proliferation.

The combined effect of TQ and CDDP on cell proliferation was most noticeable at 48 and 72 hrs with $89 \%$ inhibition of cell proliferation observed at $72 \mathrm{hrs}$ (Figure 1, Figure 2, Figure 3).

\section{2) TQ enhances the effect of Cisplatin with synergism between the two agents}

When the NCI-H460 cells were grown in the presence or absence of TQ and CDDP it was apparent that the combined effect of TQ and CDDP was more than the each agent alone. To confirm the presence of synergism we determined the Combination index (CI) for two combination treatment groups using Calcuysyn software with $\mathrm{CI}<1$ indicating synergism, $\mathrm{CI}>1$ indicating antagonism and $\mathrm{CI}=1$ indicating an additive effect.

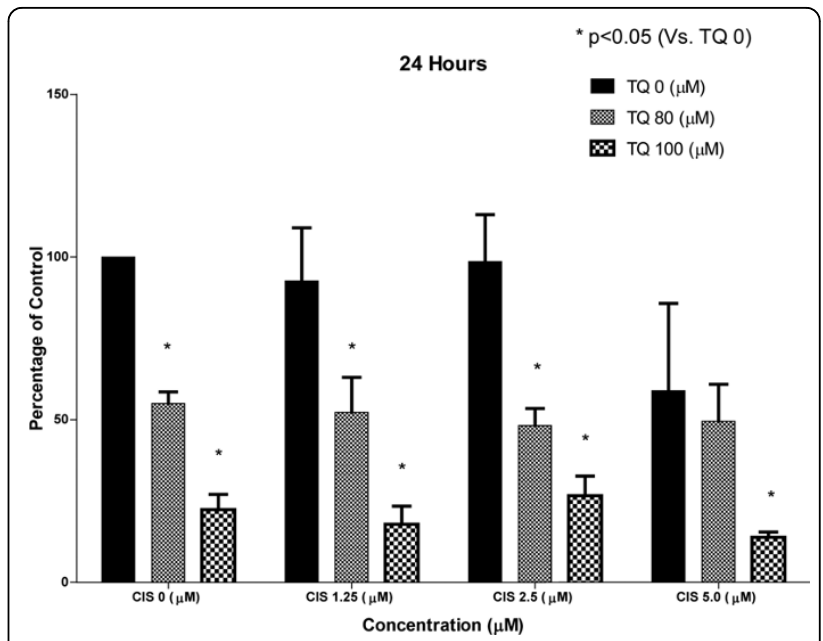

Figure 1 The figure shows results of MTT assay for cell proliferation using NSCLC cell line NCI-H460 at 24, 48 and 72 hrs with control group representing $100 \%$ cell proliferation depicted by extreme left solid line. TQ alone is more active at 24 hrs and CDDP more active at 48 and 72 hrs. The combination of TQ and CDDP is more active than each agent alone with up to $89 \%$ inhibition of cell proliferation at 72 hrs with combination of TQ 100 $\mu \mathrm{M}$ and CDDP $5 \mu \mathrm{M}$. $\left(^{*}\right)$ shows significant inhibition by TQ at each level of CDDP $(p<0.05)$.

Synergism was most noticeable at 72 hrs in the groups TQ 80 and CDDP $1.25(\mathrm{CI}=0.789)$ (Figure 4) as well as TQ 100 and CDDP $2.5(\mathrm{CI}=0.761)$.

The combination of TQ $(100 \mu \mathrm{M})$ and CDDP $(5 \mu \mathrm{M})$ at 72 hrs showed $89 \%$ inhibition of cell proliferation (Figure 3).

\section{3) TQ inhibits cell viability in a SCLC cell line}

Measurements of cell viability in a SCLC cell line NCIH146 were determined using trypan blue assay. $24 \mathrm{hrs}$ after exposure to TQ 20-100 uM on average only $50 \%$ of cells were viable as shown in (Figure 5).

\section{4) Apoptosis assay}

To determine if the decrease in proliferation and viability were a result of TQ induced apoptosis in the two cell lines, cells were assayed by Annexin V staining after exposure to TQ. After 24 hours treatment with $100 \mu \mathrm{M}$ TQ about $87.59 \%$ of NCI-H460 cells and $88.1 \%$ of NCI$\mathrm{H} 146$ cells were positive for Annexin-V compared to $2.0 \%$ and $34.5 \%$ Annexin $\mathrm{V}$ positive cells in the DMSO treated cell (Figure 6).

\section{3) TQ suppresses expression of cytokines involved in neo-angiogenesis}

To assess the effect of TQ on release of various cytokines we assayed the culture media to determine if TQ affected expression of cytokines in NCI-H460 cell line. Of the panel of various cytokines measured using 


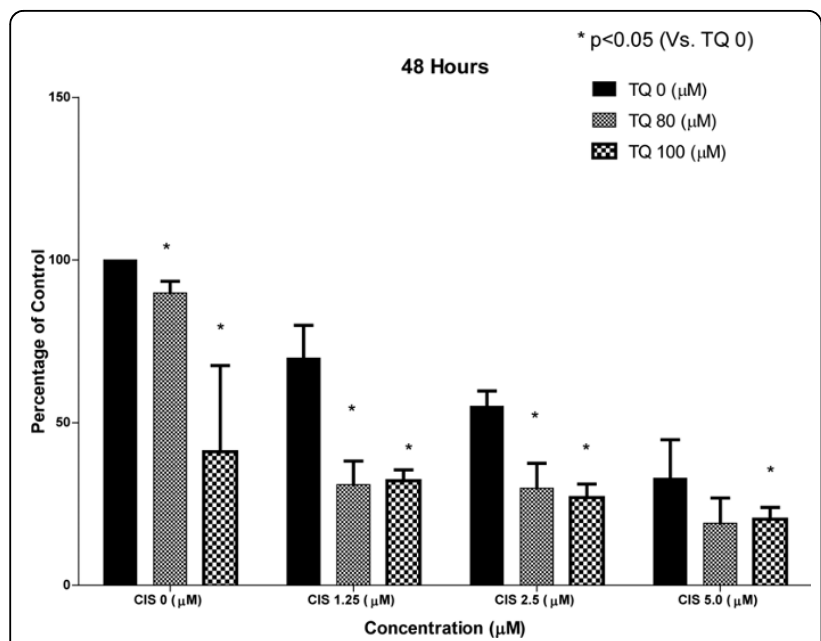

Figure 2 The figure shows results of MTT assay for cell proliferation using NSCLC cell line $\mathrm{NCl}-\mathrm{H} 460$ at 24, 48 and 72 hrs with control group representing $100 \%$ cell proliferation depicted by extreme left solid line. TQ alone is more active at 24 hrs and CDDP more active at 48 and 72 hrs. The combination of TQ and CDDP is more active than each agent alone with up to $89 \%$ inhibition of cell proliferation at $72 \mathrm{hrs}$ with combination of TQ 100 $\mu \mathrm{M}$ and CDDP $5 \mu \mathrm{M}$. $\left(^{*}\right)$ shows significant inhibition by TQ at each level of CDDP $(p<0.05)$.

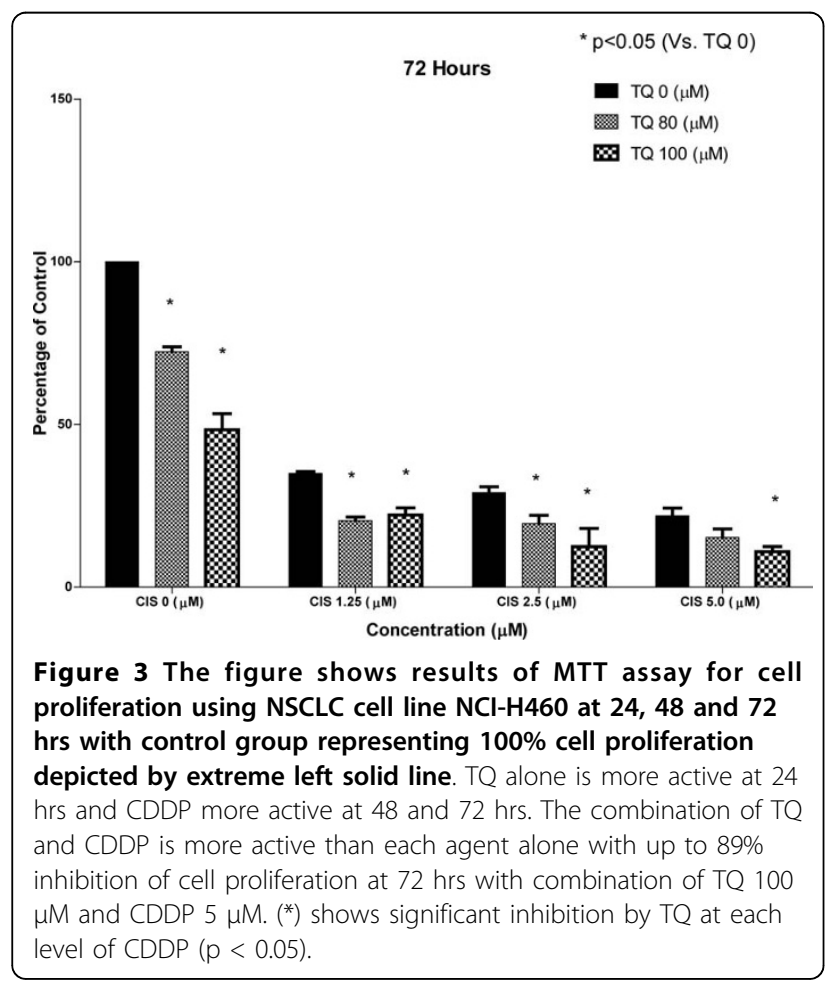

RayBio Human Cytokine Antibody Array C Series 2000, two cytokines ENA-78 and Gro-alpha were significantly lower in the media of cells exposed to $100 \mu \mathrm{M}$ TQ as compared to control. The mean integrated density as

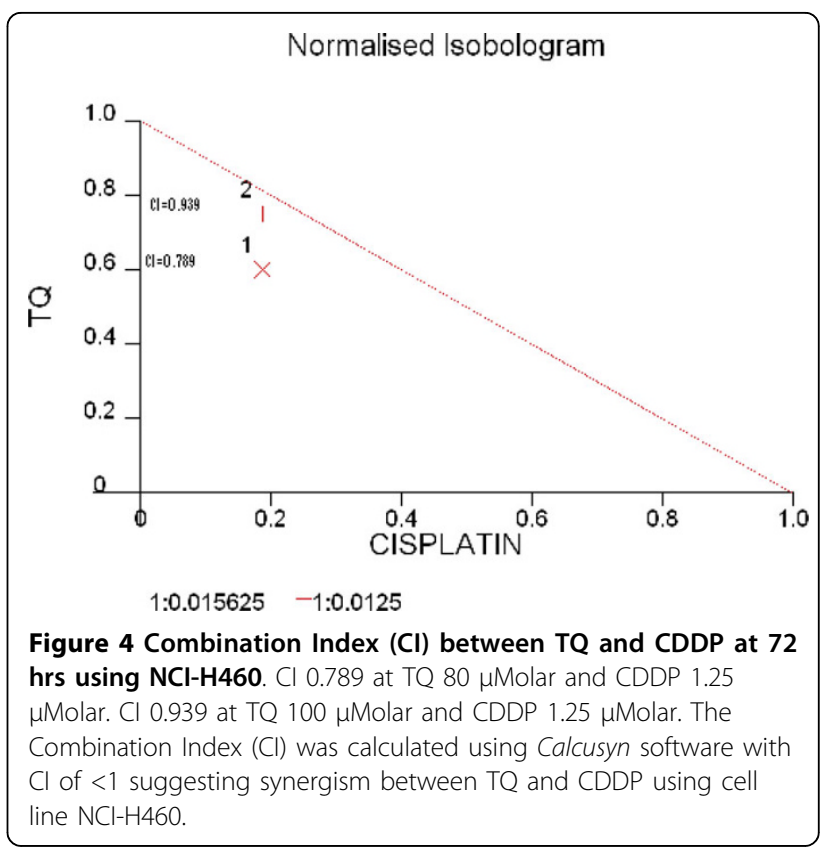

measured by Image J Software for ENA-78 in the control treated group was 7083 as compared to 1732 in the TQ treated group and for Gro-alpha in the control group mean integrated density was 9970 as compared to 1877 in the TQ treated group (See figure 7-8).

\section{4) TQ inhibits invasion in a Matrigel assay}

Because of the known effects of TQ on decreasing specific cytokines production and the known effects of cytokines on tumor cell invasion, we determined the effects of TQ on tumor cell invasion as assayed by growth into Matrigel. TQ at three concentrations (20, 40 and 80 $\mu \mathrm{M})$ significantly inhibited invasion as compared to control $(\mathrm{P}<0.05)$. Inhibition of invasion was greatest at 40 $\mu \mathrm{M}$ where inhibition was $85 \%$ as compared to control (Figure 9).

\section{5) Maximum tolerated dose (MTD) and toxicity study}

Prior to determining the effect of TQ on the growth of xenografts we studied the toxicity of TQ and CDDP alone and in combination as noted in the Methods to determine the maximum tolerated dose (MTD). Besides vehicle control (group 1), TQ was administered (s.c) on Monday, Wednesday, and Friday for 3 weeks at doses of $5 \mathrm{mg} / \mathrm{kg}$ (group2), $10 \mathrm{mg} / \mathrm{kg}$ (group3) and $20 \mathrm{mg} / \mathrm{kg}$ (group4). CDDP was administered (i.p) once a week for 3 weeks at $5 \mathrm{mg} / \mathrm{kg}$ (group 5) alone or in combination with TQ at $5 \mathrm{mg} / \mathrm{kg}$ (group 6), $10 \mathrm{mg} / \mathrm{kg}$ (group 7) and $20 \mathrm{mg} / \mathrm{kg}$ (group 8). No mortality was observed in groups 1-6 though mice in group 6 lost 20-40\% of body weight. $50 \%$ of the mice in group 7 and $75 \%$ in group 8 died. Histological analysis was performed on kidneys, 


\section{Trypan blue assay}

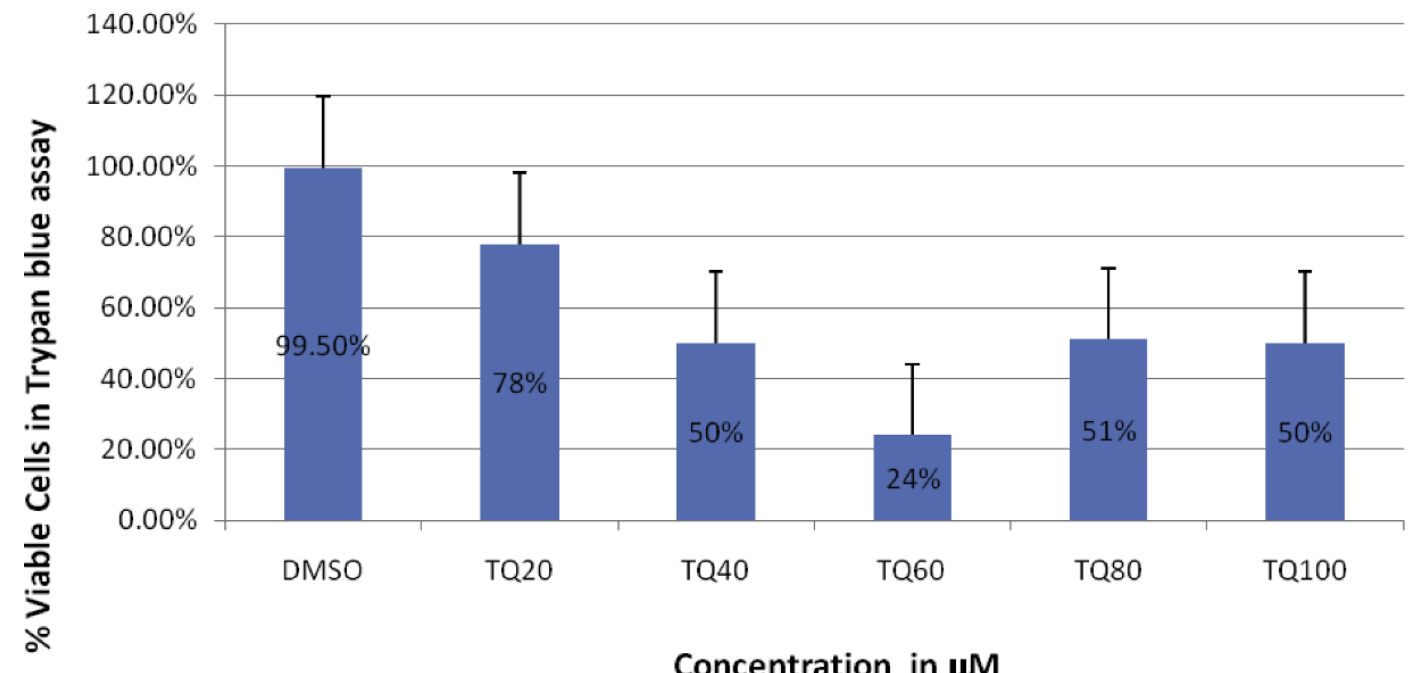

Figure 5 Results of trypan blue cell viability assay using SCLC cell line NCI-H460 2 hrs after treatment with increasing concentration of TQ. Cell viability decreased with increasing concentration of TQ and on average only $50 \%$ of cells were viable 2 hrs after treatment with various concentration of TQ.
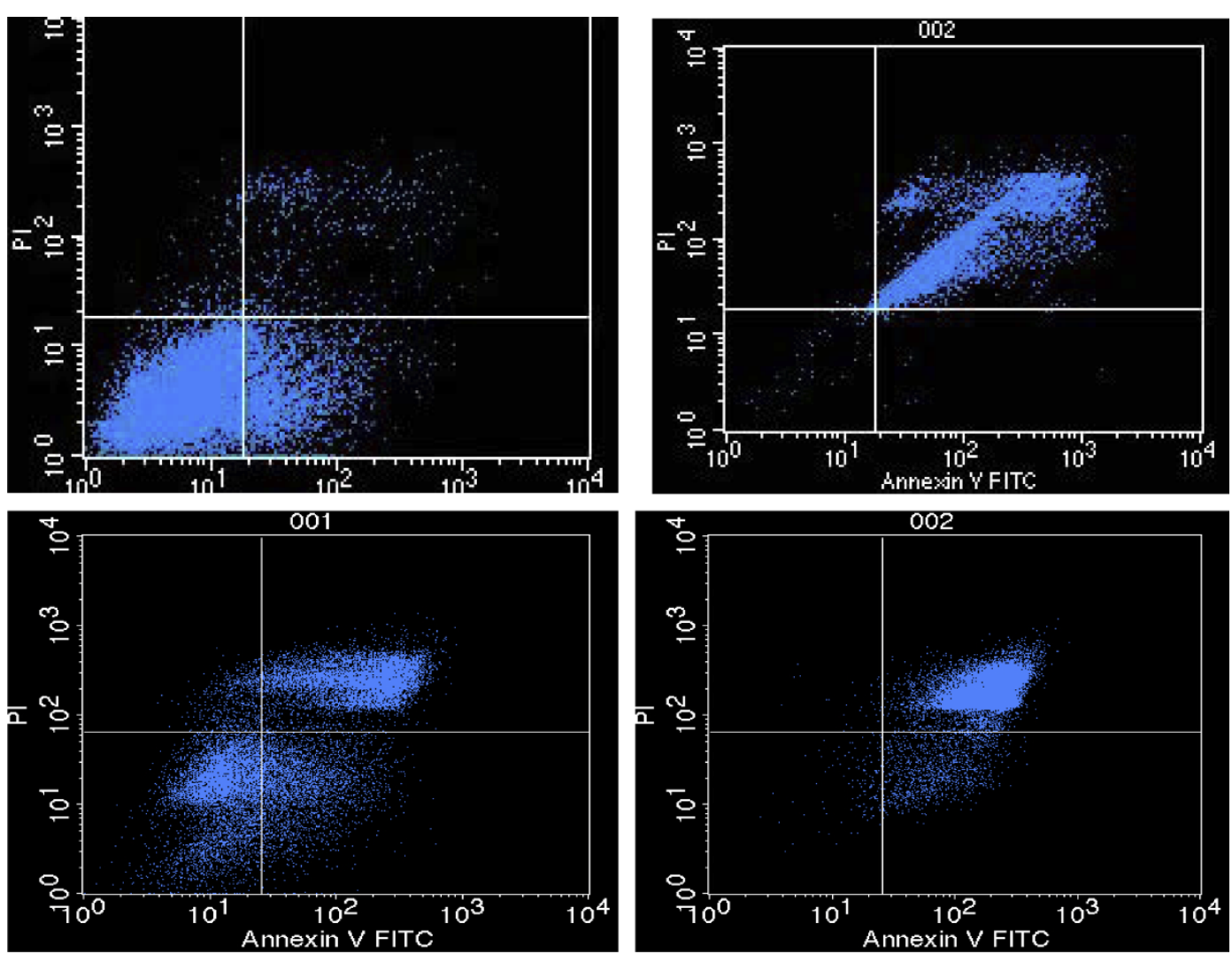

Figure 6 Flowcytometry data showing apoptosis in both NSCLC (NCI-H460) and SCLC (NCI-H146) cell lines 24 hrs after treatment with TQ $100 \mu \mathrm{M} . \mathbf{8 7 . 5 9 \%}$ of $\mathrm{NCl}-\mathrm{H} 460$ cells and $\mathbf{8 8 . 1} \%$ of $\mathrm{NCl}-\mathrm{H} 146$ cells were positive for Annexin-V 24 hrs after treatment with TQ. Upper row represent $\mathrm{NCl}-\mathrm{H} 460$ cells and Lower row NCl-H146. Left column represents control treated and the right column represents TQ treated. 


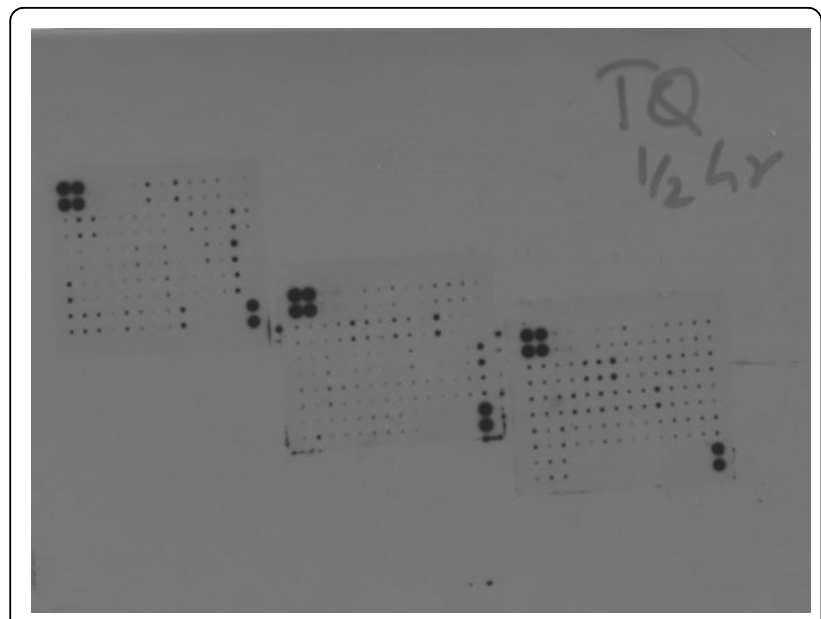

Figure 7 Effect of TQ on release of various cytokines was determined using RayBio Human Cytokines Antibody Array C Series 2000. TQ treated cell media was applied to cytokine membranes which were then exposed to a photographic film for 30 minutes and developed in a dark room. The three membranes represent various cytokines whose presence can be detected using this technique. Dots represent presence or absence of various cytokines which were then quantitated using image J Software expressed as mean integrated density.

liver, lung and heart of treated mice. There were no pathological abnormalities noted in the lungs and heart of any of the mice. In the analysis of the kidneys no pathological abnormality was observed in groups 1-4 (TQ treated alone) except for the presence of $5 \%$ focal proximal tubular damage noted in group 4 (TQ $20 \mathrm{mg} /$ $\mathrm{kg})$. In group 5 (CDDP $5 \mathrm{mg} / \mathrm{kg}$ alone) there was proximal tubular damage noted in $20-30 \%$ of the samples. In the combination groups $[7,8]$ diffuse tubular damage and acute tubular necrosis (ATN) was noted in $40-80 \%$ of samples. Mice in these groups also lost significant body weight and appeared dehydrated. This enhancement of nephrotoxicity may be related to poor by mouth intake and dehydration resulting in ATN. On the

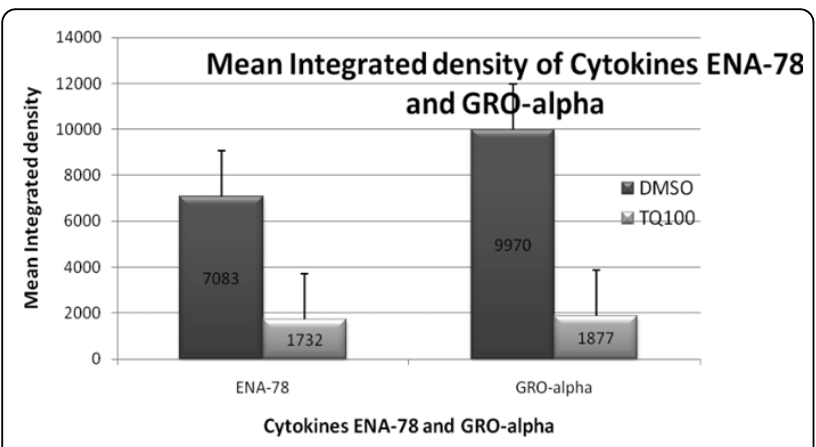

Figure 8 TQ suppressed expression of cytokines ENA-78 and GRO-alpha significantly as compared to control. These cytokines are implicated in neo-angiogenesis.

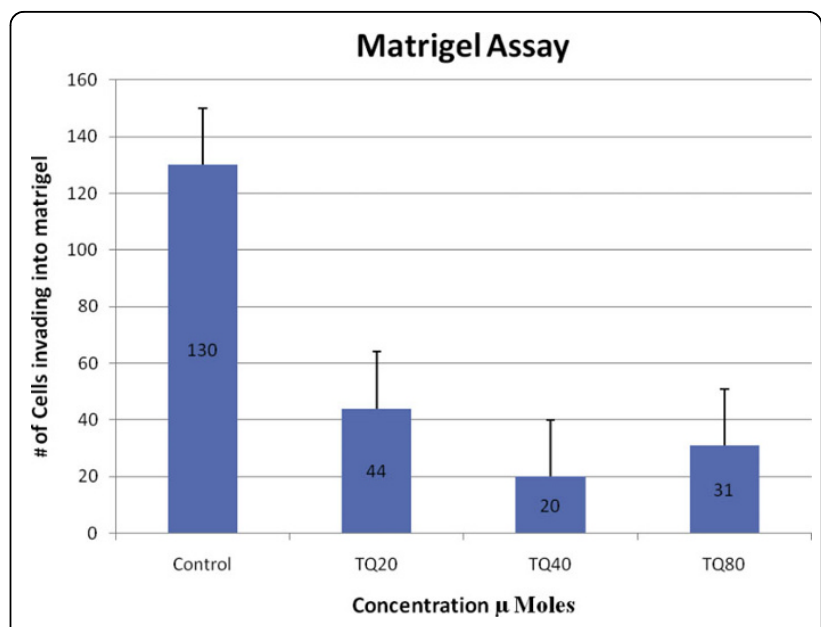

Figure 9 Effect of TQ on invasion was assessed calculating number of cells invading into Matrigel. TQ at increasing concentration inhibited cell invasion as compared to control.

basis of these studies MTD was determined to be as follows: CDDP $2.5 \mathrm{mg} / \mathrm{kg}$ i.p. weekly along with TQ at $5 \mathrm{mg} / \mathrm{kg}$ and $20 \mathrm{mg} / \mathrm{kg}$ subcutaneously Monday, Wednesday and Friday for the xenograft study.

\section{6) Mouse xenograft study}

In the mouse xenograft study as described in methods section after 4 weeks of tumor growth no mortality occurred. However, the combination of TQ and CDDP had striking effects on tumor volume (Figure 10). TQ alone at $5 \mathrm{mg} / \mathrm{kg}$ was not active. The higher dose of TQ

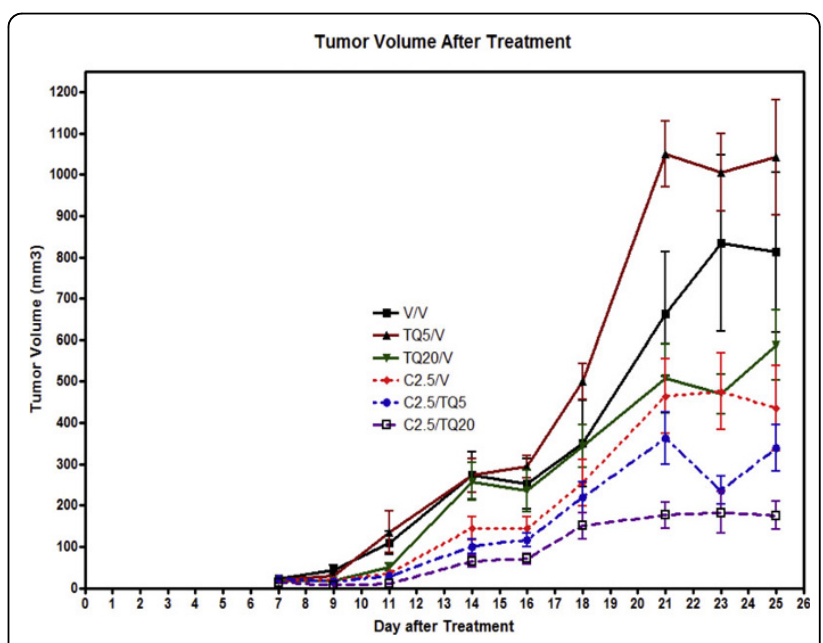

Figure 10 Results of Mouse xenograft study. Tumor volume with time: Change in tumor volume is shown in various treatment arms over the study period. Mice were treated with either s.c. TQ every Monday, Wednesday and Friday or CDDP i.p. once a week or combination.Mice in combination treatment arms (TQ20 mg/kg + CDDP $2.5 \mathrm{mg} / \mathrm{kg}$ ) had the smallest tumor volume at the end of 3 week study period. 


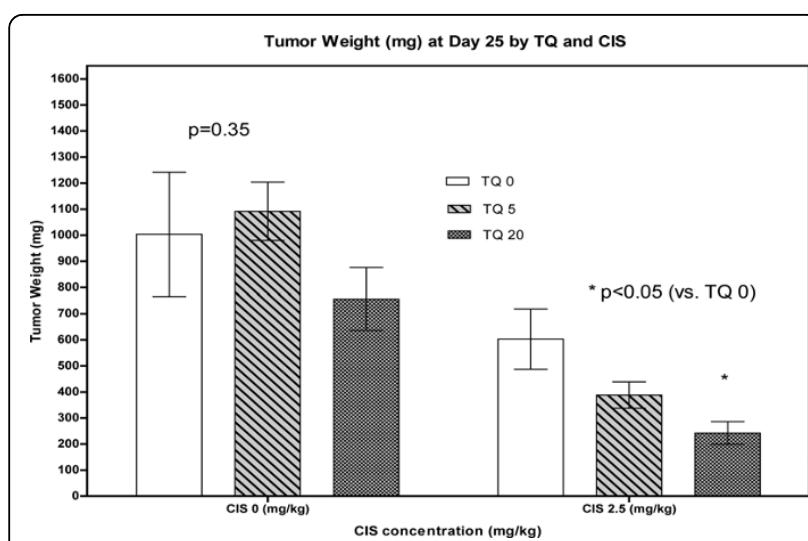

Figure 11 Mean tumor weight at day 26 for each group. $\left.{ }^{*}\right)$ means significant inhibition by addition of TQ $(p<0.05)$.

at $20 \mathrm{mg} / \mathrm{kg}$ demonstrated some activity and reduced tumor volume although the effect was marginally significant ( $\mathrm{p}$ 0.075). Cisplatin alone at $2.5 \mathrm{mg} / \mathrm{kg}$ reduced tumor volume significantly $(\mathrm{p}<0.001)$. The effect on tumor volume was greatest in the combination arms with significant reduction of tumor volume by $59 \%$ with the combination of ( $5 \mathrm{mg} / \mathrm{kg}$ TQ and $2.5 \mathrm{mg} / \mathrm{kg}$ CDDP) $(\mathrm{p}=0.036)$ and by $79 \%$ with combination of $(20 \mathrm{mg} / \mathrm{kg}$ TQ and $2.5 \mathrm{mg} / \mathrm{kg}$ of CDDP) ( $\mathrm{p}=0.0016)$.

The decrease in tumor volume was mimicked by a similar decrease in tumor weight in all treatment arms except TQ alone at $5 \mathrm{mg} / \mathrm{kg}$ (Figure 11).

\section{7) TQ suppresses $\mathrm{NF}-\kappa \mathrm{B}$ expression in vivo}

TQ by itself had no effect on basal luciferase activity and NF- $\kappa \mathrm{B}$ expression. (Figure 12 top panels). However, at $3 \mathrm{hrs}$ after treatment with LPS the increased luminescence indicating activation of NF- $\kappa \mathrm{B}$ was suppressed by prior treatment with TQ at 5 and $20 \mathrm{mg} / \mathrm{kg}$ as compared to control though this effect was not statistically significant $(\mathrm{P}<0.10)$. This effect however was not observed at 24 hrs point interval, where most of luminescence had returned to baseline (Figure 12, Table 1).

\section{8) Effect of TQ on expression of NF- $\kappa$ B in the xenografts}

The xenografts were further evaluated for the effects of TQ on NF- $\kappa$ B expression with tumor lysates from xenografts analyzed by western blot for levels of phosphorylated NF- $\kappa \mathrm{B}$ as a ratio of total NF- $\kappa \mathrm{B}$. Significant reduction in ratio of phosphor-Ser $529 \mathrm{NF}-\kappa \mathrm{B} / \mathrm{NF}-\kappa \mathrm{B}$ were seen in xenografts from mice treated with combination of TQ $(20 \mathrm{mg} / \mathrm{kg})$ and CDDP $(2.5 \mathrm{mg} / \mathrm{kg})$ but not with TQ or CDDP alone $(\mathrm{P}<0.05)$ (Figure 13).

\section{Discussion}

We evaluated anti-neoplastic effect of TQ alone and more importantly in combination with CDDP in a
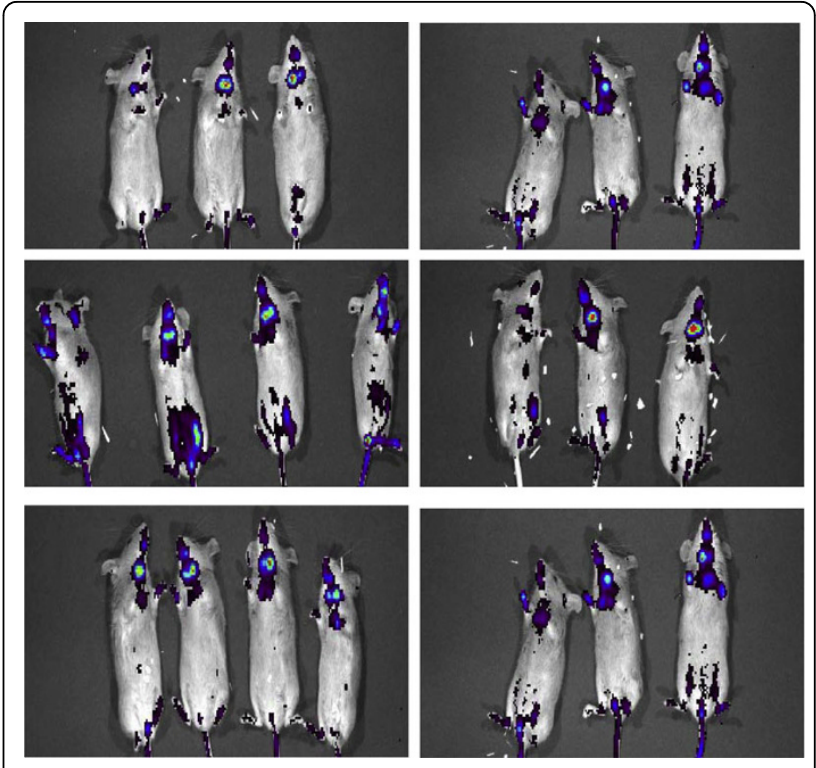

Figure 12 LPS induced NF- $\kappa$ B expression using luciferase reporter mice. Upper row: NF- $\kappa$ B expression pre-screen; Middle row NF- $\kappa$ B expression 3 hrs after LPS induction; Lower row NF- $\kappa B$ expression 24 hrs after LPS induction. Mice when pre-treated with TQ $5 \mathrm{mg} / \mathrm{kg}$ (Right column) showed less NF- $\kappa$ B expression at $3 \mathrm{hrs}$ as compared to control treat mice (Left column). Level of NF- $\kappa B$ expression returned to baseline $24 \mathrm{hrs}$ after exposure to LPS. The luminescence from luciferase was detected real time using an ultrasensitive camera IVIS 100 Imaging system. The luminescence intensity was quantitated in regions of interest (ROI) using Living Image ${ }^{\oplus} .0$ software as shown in table 1.

NSCLC and a SCLC lung cancer cell line using both in vitro and in vivo techniques. TQ appeared to be active both in a NSCLC and a SCLC cell line. TQ inhibited proliferation of NSCLC cell line NCI-H460 and induced apoptosis. Similarly cell viability of SCLC cell lines NCIH146 was decreased and cells underwent apoptosis after exposure to TQ. More importantly TQ acted synergistically with CDDP in a NSCLC cell line which is very encouraging. This inhibitory effect of TQ on lung cancer cell proliferation is not unique as recently TQ has been shown to inhibit growth of prostate, pancreatic and colon cancers [11] However, this is the first time that we have demonstrated anti-neoplastic effects of TQ in Lung Cancer using both a NSCLC and a SCLC cell line. Combination of TQ and CDDP is also unique and the results are encouraging as the two drugs have differing mechanism of action, the former being a cell cycle specific and the latter non-cell cycle specific. The dose of TQ used in these experiments may not be feasible in humans. Recently, Banerjee et al [21] have shown that more potent synthetic analogues of TQ can be prepared which can potentially be developed for future human use.

Besides anti-proliferative and pro-apoptotic effects TQ appears to affect tumor microenvironment. TQ reduced 
Table 1 ROI values of Female Luciferase reporter mice*

\begin{tabular}{llll}
\hline & Control & TQ5 $\mathbf{~ m g} / \mathbf{k g}$ & TQ20 mg/kg \\
\hline Pre-Screen & $15,490+/-2,108$ & $17,155+/-8,957$ & $11,990+/-3,031$ \\
\hline LPS 3 hrs & $176,375+/-63,901$ & $89,457+/-24,084$ & $75,923+/-33,793$ \\
\hline LPS 24 hrs & $23,978+/-5,501$ & $24,177+/-6,830$ & $39,823+/-13,631$ \\
\hline
\end{tabular}

$\mathrm{NF}-\kappa \mathrm{B}$ expression was measured by quantitating the luminescence intensity in regions of interest (ROI) using Living Image ${ }^{\oplus} 3.0$ software (Caliper Life Sciences, Inc. Hopkinton, MA). $\left.{ }^{*}\right)$ ROI values include $+/$ - standard error $(n=3-4)$ obtained using Living Image Software version 3.0. ROI values are equal in the mice pretreated with vehicle or TQ showing TQ has no effect on NF- $\kappa$ B expression. 3 hrs after LPS injection ROI values representing NF- $\kappa$ B expression are much lower in mice pre-treated with TQ at 5 and $20 \mathrm{mg} / \mathrm{kg}$ though not statistically significant $(P<0.10)$ as compared to control suggesting pre-treatment with $\mathrm{TQ}$ suppresses $\mathrm{NF}-\kappa \mathrm{B}$ expression. $\mathrm{ROI}$ return to baseline at $24 \mathrm{hrs}$ in both groups.

the release of two cytokines ENA-78 and Gro-alpha which are involved in inflammation and angiogenesis [22]. ENA-78 has been shown to be elevated in NSCLC surgical samples and correlates with tumor growth and vascularity [23]. ENA-78 and GRO belong to a family of ELR+ve CXC cytokines and are potent promoters of angiogenesis [24]. Similarly using Matrigel assay we were able to demonstrate that TQ inhibited invasion of NCI-H460 cells into Matrigel. Inhibition of tumor angiogenesis by TQ and its effects on invasion have recently been shown by others as well [25]. Thus TQ appears to be an agent that not only affects cell proliferation but may also influence the extra-cellular environment and immune system.

As far as toxicity from TQ is concerned there appears to be no significant toxicity demonstrated from use of TQ alone in our MTD study using female SCID mice. When TQ was used alone no mortality was observed, mice maintained their weight and no significant tissue damage was observed on histological analysis of liver and kidney. In the MTD study where a higher dose of CDDP $(5 \mathrm{mg} / \mathrm{kg}$ ) was used in combination with TQ mortality was observed in mice and most of the tissue damage was noticed to be in kidneys. It appears that the

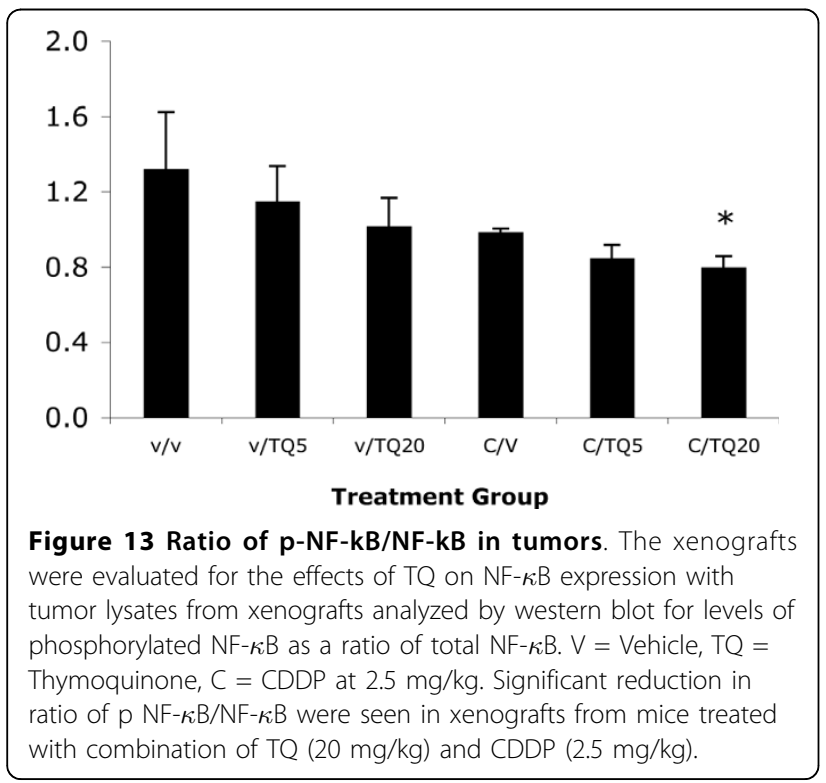

nephroprotective effects of TQ against CDDP as demonstrated in a previous study [12] were not reproduced in our model. The Combination of TQ with higher doses of CDDP also contributed to significant weight loss and apparent dehydration which may have resulted in worsening of kidney damage from CDDP and ultimately their demise. However, TQ alone or in combination with lower dose of CDDP ( $2.5 \mathrm{mg} / \mathrm{kg}$ i.p. weekly) did not appear to have any direct toxic effect on kidneys or liver. In the mouse xenograft model in combination with CDDP at $2.5 \mathrm{mg} / \mathrm{kg}$ there was weight loss but no mortality or tissue damage was observed on histological analysis of kidneys and liver.

In the mouse xenograft model TQ alone at $20 \mathrm{mg} / \mathrm{kg}$ was active. The combination of TQ and CDDP was more active than each agent alone. The combination of $(20 \mathrm{mg} / \mathrm{kg}$ TQ and $2.5 \mathrm{mg} / \mathrm{kg}$ of CDDP) reduced tumor volume by $79 \%$ without additional toxicity to the mice. These results are very encouraging and consistent with our in vitro data and show that TQ and CDDP is an effective therapeutic combination in lung cancer.

TQ by itself was shown to suppress LPS-induced NF$\kappa \mathrm{B}$ activation in the NF- $\kappa \mathrm{B}$-Luc-Re mice which is consistent with known properties of TQ [16]. We substantiated this finding in the luciferase mouse with the analysis of $\mathrm{p}-\mathrm{NF}-\kappa \mathrm{B}$ expression in lysates of the xenografts (Figure 13). The effect on NF- $\kappa \mathrm{B}$ was present in the combination of CDDP and TQ as presumably the combination is blocking multiple pathways that activate the NF- $\kappa \mathrm{B}$. As altered NF- $\kappa \mathrm{B}$ expression is implicated in CDDP resistance [14] the suppression of NF- $\kappa \mathrm{B}$ by TQ may provide a mechanism for overcoming CDDP resistance which makes TQ an exciting compound to develop in combination with CDDP. Supporting our results is recent publication by Banerjee et al [26] in which TQ was shown to augment anti-tumor activity of Gemcitabine and Oxaliplatin in pancreatic cancer by down regulation of NF- $\kappa \mathrm{B}$.

Recently it has been shown that the effects of TQ are broad with the demonstration that TQ inhibits Polo like kinases (PLKs) [27], family of serine/threonine protein kinases which control critical steps in passage of cells through the M phase of the cell cycle [28].Also PLK1 is 
over expressed in NSCLC and has prognostic significance [29]. Therefore in using TQ in NSCLC we may target cell cycle not only at G1-S phase but also at M phase.

\section{Conclusions}

Thus in conclusion, in this paper we have demonstrated anti-proliferative and pro-apoptotic activities of TQ in both a NSCLC and a SCLC cell lines. It also appears that there may be synergism between TQ and CDDP. This combination was active in vivo as demonstrated by the mouse xenograft sudy. By suppressing NF- $\kappa \mathrm{B}$, TQ may be able to overcome CDDP resistance and enhance its efficacy. Thus TQ or likely synthetic analogues of TQ should be developed for possible future human use not only in lung cancer but in possibly other tumor types as well.

\section{Source of Funding}

Syed H. Jafri received fellowship grant from Amgen Inc.

\begin{abstract}
Abbreviations
(NSCLC): non-small cell lung cancer; (SCLC): small cell lung cancer; (TQ): Thymoquinone; (EAC): Ehrlic ascites sarcoma; (CDDP): Cisplatin; (PLKs): Polo like kinases; (ATCC): American type culture collection; (FBS): Fetal bovine serum; (DMSO): Dimethyl Sulfoxide; (MTT): 3-(4,5 Dimethylthiazol -2-yl)-2,5dipheynyltetrazolium bromide; (SCID): Severe combined immunodeficiency; (NIH): National institute of health; (MTD): Maximum tolerated dose; (LPS): Lipopolysaccharide; (LPTA): light producing animal model; (TNF- $\alpha$ ): Tumor necrosis factor-alpha; (Cl): Combination index; (ANOVA): Factorial analyses of variance; (PI): Propidium iodide; (ATN): acute tubular necrosis; (NIH): National Institutes of Health; (NF- $\kappa \mathrm{B})$ : Nuclear Factor kappa-B.
\end{abstract}

\section{Acknowledgements}

We acknowledge Dr Francesco Turturro and his associate Ms. Ellen Friday from LSUHSC-Shreveport for their help in using Calcusyn software. We appreciate the help of Ms. Tracee Terry in the small animal imaging laboratory. We also appreciate work done by student researcher Kelly Reed in Dr Kleiner- Hancock's lab in doing experiments with luciferase reporter mice.

\section{Author details}

${ }^{1}$ Feist-Weiller Cancer Center, Louisiana State University, 1501 Kings Highway, Shreveport LA, 71130 USA. ${ }^{2}$ Department of Medicine, Louisiana State University, 1501 Kings Highway, Shreveport LA, 71130 USA. ${ }^{3}$ Department of Pathology, Louisiana State University, 1501 Kings Highway, Shreveport LA 71130 USA. ${ }^{4}$ Department of Pharmacology, Toxicology and Neuroscience, Louisiana State University, 1501 Kings Highway, Shreveport, LA, USA.

\section{Authors' contributions}

SJ designed the study, carried out the experiments and wrote the manuscript. JG designed the study, provided guidance for the study and edited the manuscript. RS did the statistical analysis and made illustrations and graphs. SZ did histological analysis of tumor and tissue samples. MS helped with cell culture, western blot and mice studies. HK designed the study, carried out the experiments, wrote the manuscript and provided guidance at every step of the study. All authors have read and approved the final manuscript.

\section{Competing interests}

The authors declare that they have no competing interests.

Received: 30 May 2010 Accepted: 1 July 2010 Published: 1 July 2010
References

1. Jemal A, Seigal R, Ward E, Hao Y, Xu J, Murray T, Thun M: Cancer statistics. CA Cancer J Clin 2008, 58(2):71-96.

2. Herbst R, Heymach J, Lippman S: Lung cancer. NEJM 2008, 359:1367-80.

3. Horner MJ, Ries LAG, Krapcho M, Neyman N, Aminou R, Howlader N, et al: SEER Cancer Statistics Review National Cancer Institute. Bethesda, MD 1975.

4. Pignon JP, Tribodet H, Scagliotti Gi, Douillard JY, Shepherd F, Stephens R, et al: Lung Adjuvant Cisplatin Evaluation: A pooled analysis by the LACE Collaborative group. JCO 2008, 26(21):3552-3559.

5. Schiller J, Harrington D, Belani C, Langer C, Sandler A, Krook James, et al: Comparison of four chemotherapy regimens for advanced Non-Small Cell Lung Cancer. NEJM 2002, 346:92-98.

6. Klastersky J, Sculier JP, Bureau G, Libert P, Ravez P, Vandermoten G, et al: Cisplatin versus cisplatin plus etoposide in treatment of advanced Nonsmall cell lung cancer. JCO 1989, 7(8):1087-92.

7. Shepherd F, Pereira J, Ciuleanu T, Tan E, Hirsh V, Thongpraser S, et al: Erlotinib in previously treated Non-Small Cell Lung Cancer. NEJM 2005, 353(2):123-32

8. Sandler A, Gray R, Perry M, Brahmer J, Schiller J, Dowlati A, et al: Paclitaxelcarboplatin alone or with Bevacizumab in Non-Small Cell Lung cancer. NEJM 2006, 355(24):2542-2550.

9. Bhatti I, Rehman F, Khan M, Marwa S: Effect of Prophetic medicine Kalonji (Nigella sativa L.) on Lipid profile of human beings: An In Vivo Approach World Applied Sciences Journal 2009, 6(8):1053-1057.

10. Gali-Muhtasib H, Roessner A, Schneider-stock R: Thymoquinone: A promising anti-cancer drug from natural sources. The international Journal of Biochemistry and Cell Biology 2006, 38:1249-1253.

11. Paydhye S, Banerjee S, Ahmen A, Mohamad R, Sarkar F: From here to eternity. The secret of Pharaohs: Therapeutic potential of black cumin seeds and beyond. Cancer Ther 2008, 6(b):495-510.

12. Badary OA, Naqi MN, Al-Shabanah OA, Al-Sawaf HA, Al- Sohaibani MO, AlBekairi MA, et al: Thymoquinone ameliorates the nephrotoxicity induced b Cisplatin in rodents and potentiates its anti tumor activity. Canadian Journal of Physiology and Pharmacology 1997, 75:1356-1361.

13. Wang D, Lippard S: Cellular processing of platinum anticancer drugs. Nature reviews, drug discovery 2005, 4:307-320.

14. Rong R, He Q, Liu Y, Sheikh MS, Hang Y: TC21 mediates transformation cell survival via activation of phophotidylinositol 3-kinase/Akt and NF- $\kappa$ B signaling pathway. Oncogene 2002, 21:1062-1070.

15. Karin M, Cao Y, Greten F, Li Z: NF- $\kappa$ B in cancer: From innocent bystander to major culprit. Nature reviews cancer 2002, 2:301-10.

16. Sethi G, Ahn KS, Aggarwal BB: Targeting nuclear factor- $\kappa$ B activation pathway by thymoquinone: role in suppression of antiapoptotic gene products and enhancement of apoptosis. Mol Cancer res 2008, 6(6):1059-70.

17. Laemmli UK: Cleavage of structural proteins during the assembly of the head of bacteriophage T4. Nature 1970, 227:680-5.

18. Towbin $H$, Staehelin $T$, Gordon J: Electrophoretic transfer of proteins from polyacrylamide gels to nitro cellulose sheets. Procedure and some applications. Proc Natl Acad Science 1979, 76(9):4350-4.

19. Kleiner HE, Reed MJ, DiGiovanni J: Naturally occurring coumarins inhibit human cytochromes P450 and block benzo[a]pyrene and 7,12dimethylbenz[a]anthracene DNA adduct formation in MCF-7 cells. Chem Res Toxicol 2003, 6:415-22.

20. Carlsen H, Moskaug J, Fromm SH, Blomhoff R: In Vivo Imaging of NF- $\kappa$ B activity. J of Immunol 2002, 168:1441-1446.

21. Sanjeev Banerjee, Azmi SAsfar, Subash Padhye, Singh WMarjit, Baruah BJubaraj, Phillip APhillip, Sarkar HFazlul, Mohammad MRamz: Structure-Activity Studies on Therapeutic Potential of Thymoquinone Analogs in Pancreatic Cancer. Pharm Res 2010, 27:1146-1158.

22. Ahuja SK, Murphy PM: The CXC chemokines growth-regulated oncogene (GRO), GRO $\alpha, G R O$, neutrophil-activating peptide-2, and epithelial cellderived neutrophil-activating peptide-78 are potent agonist for the type B, but not the type A, human interleukin-8 receptor. J Biol Chem 1996, 271:20545-50.

23. Arenberg DA, Keane MP, DiGivonie B, Kunker SL, Morris SB, Xue YY, et al: Epithelial neutrophil activating peptide (ENA-78) is an important angiogenic factor in non-small cell lung cancer. J Clin Invest 1998, 1 102(3):465-472. 
24. Strieter RM, Polverini PJ, Kunkel SL, Arenberg ADouglas, Burdick DMarie, James Kasper, et al: The functional role of the ELR motif in CXC chemokine-mediated angiogenesis. J Biol Chem 1995, 270:27348-57.

25. Yi T, Cho SG, Yi Z, Pang X, Rodriguez M, Wany Y, Sethi G, Aggarwal BB, Liu M: Thymoquinone inhibits tumor angiogenesis and tumor growth through suppressing AKT and extracellular signal-regulated kinase signaling pathways. Mol Cancer Ther 2008, 7(7):1789-96

26. Banerjee S, Kaseb A, Wang Z, Kong D, Mohammad M, Padhye S, et al: Anti tumor activity of Gemcitabine and Oxaliplatin is augmented by Thymoquinone in Pancreatic Cancer. Cancer Res 2009, 69(13):5575-5583.

27. Reindl W, Yuan J, Kramer A, Srebhardt K, Berg T: Inhibition of Polo-like kinase 1 by blocking Polo-Box Domain-dependant Protein-protein interactions. Chemistry \& Biology 2008, 15:459-466.

28. Strebhardt K, Ullrich A: Targeting polo-like kinase 1 for cancer Therapy. Nature reviews cancer 2006, 6:321-330.

29. Wolf $G$, Elez R, Doermer A, Holtrich U, Ackermann H, Stutte $H$, et al: Prognostic significant of polo-like kinase (PLK) expression in Non-small cell lung cancer. Oncogene 1997, 14:543-549.

doi:10.1186/1756-9966-29-87

Cite this article as: Jafri et al:: Thymoquinone and cisplatin as a

therapeutic combination in lung cancer: In vitro and in vivo. Journal of Experimental \& Clinical Cancer Research 2010 29:87.

\section{Submit your next manuscript to BioMed Central and take full advantage of:}

- Convenient online submission

- Thorough peer review

- No space constraints or color figure charges

- Immediate publication on acceptance

- Inclusion in PubMed, CAS, Scopus and Google Scholar

- Research which is freely available for redistribution

Submit your manuscript at www.biomedcentral.com/submit 